\title{
A INCLUSÃO NA PRÉ-ESCOLA OBRIGATÓRIA: UMA ANÁLISE DA LEGISLAÇÃO
}

\author{
LA INCLUSIÓN EN LA PRE-ESCUELA OBLIGATORIA: UN ANÁLISIS DE LA \\ LEGISLACIÓN
}

\author{
INCLUSION IN THE MANDATORY PRE-SCHOOL: AN ANALYSIS OF \\ LEGISLATION
}

RESUMO: O objetivo desse estudo de caráter bibliográfico é discutir os impactos da obrigatoriedade da pré-escola na ação dos professores e os desafios para a concretização de um trabalho pedagógico inclusivo de qualidade, que promova o desenvolvimento integral de todas as crianças, independente de sua condição física ou intelectual. Isso porque, embora a legislação e as políticas públicas reconheçam a criança como sujeito de direitos, inclusive o direito à educação desde o nascimento, verifica-se também um retrocesso nas medidas legais, haja vista que a Emenda Constitucional $n^{\circ}$. 59/09 determina a matrícula obrigatória a partir dos quatro anos de idade; o que pode levar à fragmentação do trabalho pedagógico entre a creche e pré-escola, bem como a antecipação da escolarização e alfabetização precoce.

PALAVRAS-CHAVE: Inclusão. Direitos. Obrigatoriedade. Legislação.

RESUMEN: El objetivo de este estudio de carácter bibliográfico es discutir los impactos de la obligatoriedad de la preescolar en la acción de los profesores y los desafíos para la concreción de un trabajo pedagógico inclusivo de calidad que promueve el desarrollo integral de todos los niños independientemente de su condición física o intelectual. Esto porque, aunque la legislación y las políticas públicas reconocen al niño como sujeto de derechos, incluso el derecho a la educación desde el nacimiento, se verifica también un retroceso en las medidas legales, teniendo en cuenta que la Enmienda Constitucional $n^{o}$ 59/09 determina la matrícula obligatoria a partir de los cuatro años de edad; lo que puede llevar a la fragmentación del trabajo pedagógico entre la guardería y preescolar, así como la anticipación de la escolarización y alfabetización precoz.

PALABRAS CLAVE: Inclusión. Derechos. Obligatorio. Legislación.

ABSTRACT: The objective of this bibliographic study is to discuss the impacts of pre-school compulsion on teachers' actions and the challenges to the accomplishment of an inclusive quality pedagogical work that promotes the integral development of all children, regardless of their physical condition or intellectual. This is because, although legislation and public

${ }^{1}$ Universidade Estadual de Londrina (UEL), Londrina - PR- Brasil. Professora Adjunta no Departamento de Educação e no Programa de Pós-Graduação - Mestrado em Educação. ORCID: <https://orcid.org/0000-00027961-2362>. E-mail: jaquelinedelgado@uol.com.br 
policies recognize children as subjects of rights, including the right to education from birth, there is also a setback in legal measures, since Constitutional Amendment No. 59/09 determines enrollment compulsory from the age of four; which may lead to the fragmentation of pedagogical work between kindergarten and pre-school, as well as the anticipation of schooling and early literacy.

KEYWORDS: Inclusion. Rights. Mandatory. Legislation.

\section{Introdução}

A aprovação da Constituição Federal (1988) possibilitou a superação da função assistencialista, até então presente nas instituições de atendimento à criança pela função pedagógica. Isso porque a LDB (1996), ao tratar da composição dos níveis escolares, insere a Educação Infantil como primeira etapa da Educação Básica e define que sua finalidade principal é promover o desenvolvimento integral da criança até cinco anos de idade, complementando a ação da família e da comunidade (BRASIL, 1996).

O direito de todas as crianças ao acesso à educação, independentemente de sua condição física ou intelectual é garantido na LDB (1996) ao definir, no artigo 58, que as necessidades educacionais especiais devem ser atendidas preferencialmente na rede regular de ensino. No inciso $3^{\circ}$, a lei determina que “[...] a oferta de educação especial, dever constitucional do Estado, tem início na faixa etária de zero a cinco, durante a Educação Infantil” (BRASIL, 1996, p. 40).

Desse modo, a superação de práticas discriminatórias e a implementação de ações inclusivas no cotidiano das escolas infantis se torna um desafio e uma necessidade primordial, visto que constata-se a contradição entre "[...] inclusão/exclusão quando os sistemas de ensino universalizam o acesso, mas continuam excluindo indivíduos e grupos considerados fora dos padrões homogeneizadores da escola" (BRASIL, 2001, p. 1).

Segundo Cury (2005), as políticas inclusivas focam na universalização de direitos civis, políticos e sociais e se amparam no papel interventor do Estado, justamente para corrigir as desigualdades. Nesse sentido "[...] elas se voltam para indivíduo e para todos, sustentadas pelo Estado, pelo princípio da igualdade de oportunidades e pela igualdade de todos ante a lei” (CURY, 2005, p. 15). Na prática, as políticas inclusivas buscam “[...] combater todas e quaisquer formas de discriminação que impeçam o acesso a maior igualdade de oportunidades e de condições" (CURY, 2005, p. 15). Ao trabalhar com o conceito de 
igualdade, as políticas includentes corrigem as fragilidades da universalidade, segundo Cury (2005), tendo em vista a redução da desigualdade social.

Para Sekkel; Zanelatto e Brandão (2010, p. 119), estar incluído não é apenas ter acesso ao espaço físico da instituição, “[...] é também ter suas necessidades percebidas e acolhidas pelos outros, é trabalhar junto, em um ambiente permeado pela confiança, pelo cuidado e pela reflexão". Por isso, o ponto de partida para a construção de um ambiente inclusivo é a consolidação do trabalho coletivo entre professores e demais envolvidos no contexto escolar, no "[...] sentido de criar escuta, possibilidades de compartilhamento e intervenção orientadas pelo compromisso com os valores humanos" (SEKKEL; ZANELATTO; BRANDÃO, 2010, p. 125).

A fim de garantir o acesso e permanência de todas as crianças na educação regular, a Política Nacional de Educação Especial na Perspectiva da Educação Inclusiva (2001), determina que “[...] o acesso à educação tem início na Educação Infantil, na qual se desenvolvem as bases necessárias para a construção do conhecimento e desenvolvimento global do aluno" (BRASIL, 2001, p. 11). Essa política reconhece a importância das atividades lúdicas e a “[...] riqueza de estímulos nos aspectos físicos, emocionais, cognitivos, psicomotores e sociais e a convivência com as diferenças que favorecem as relações interpessoais, o respeito e a valorização da criança" (BRASIL, 2001, p. 12).

Sobre essa questão, a Política Nacional de Educação Infantil (2006) ressalta que a educação de crianças com necessidades educacionais especiais "[...] deve ser realizada em conjunto com as demais crianças, assegurando-lhes o atendimento educacional especializado mediante avaliação e interação com a família e a comunidade" (BRASIL, 2006, p. 17). A integração entre instituição e família é condição necessária para a construção de um trabalho que possibilite "[...] o atendimento integral à criança, considerando seus aspectos físico, afetivo, cognitivo, sociocultural, bem como as dimensões lúdica, artística e imaginária" (BRASIL, 2006, p. 20).

Nessa perspectiva, “[...] o processo pedagógico deve considerar as crianças em sua totalidade, observando suas especificidades, as diferenças entre elas e sua forma privilegiada de conhecer o mundo por meio do brincar" (BRASIL, 2006, p. 17). A garantia da formação continuada dos professores, sobretudo no que tange aos conhecimentos específicos da área de educação especial, se faz necessária para a inclusão no contexto escolar (BRASIL, 2006).

Isso porque, apesar dos avanços das leis e das políticas públicas em relação aos direitos da criança na sociedade, verifica-se também um descompasso nas próprias 
determinações legais. O proclamado direito da criança à educação passou a ser um dever e uma obrigação dos pais na matrícula compulsória dos filhos em função da aprovação da Emenda constitucional n ${ }^{\circ} 59 / 2009$, que tornou o ensino obrigatório a partir dos quatro anos de idade no Brasil.

Vale ressaltar que a obrigatoriedade da pré-escola pode representar um retrocesso histórico e "[...] levar novamente à cisão na Educação Infantil, entre a creche e a pré-escola, e também à escolarização precoce das crianças de quatro a cinco anos de idade" (NASCIMENTO, 2011, p. 155). Para legitimar tal determinação, foi sancionada a Lei $n^{\circ}$. 12.796/2013, que altera o Art. $6^{\circ}$ da LDB (1996), e determina que é “[...] dever dos pais ou responsáveis efetuar a matrícula das crianças na educação básica a partir dos quatro anos de idade" (BRASIL, 2013, p. 2).

Farenzena (2010, p. 205) argumenta que a obrigatoriedade escolar como determinação legal atribui ao Estado o dever da oferta de vagas e de "[...] condições de qualidade que permitam o acesso, a permanência e a conclusão das etapas da escolaridade básica”. Para essa autora, não basta a legislação implementar as diretrizes e bases consistentes, mas sobretudo a “[...] efetivação da extensão da educação básica de qualidade a todos, através de políticas públicas sistemáticas e ousadas, que fraturem as persistentes desigualdades de escolarização da população brasileira" (FARENZENA, 2010, p. 206).

Nesse sentido, o objetivo desse estudo de caráter bibliográfico é discutir os impactos da obrigatoriedade na ação dos professores e os desafios para a concretização de um trabalho pedagógico inclusivo de qualidade, que promova o desenvolvimento integral de todas as crianças, independente de sua condição física ou intelectual.

Para uma melhor organização da exposição, o estudo divide-se em duas seções, sendo que, na primeira, é realizada uma análise dos avanços e retrocessos da legislação a partir da obrigatoriedade da pré-escola e os possíveis desdobramentos na ação dos professores. $\mathrm{Na}$ segunda, são desenvolvidos alguns apontamentos sobre a integração entre os cuidados, educação, brincadeiras, inclusão e o direito de todas as crianças à educação de qualidade desde o nascimento. $\mathrm{O}$ intuito é apontar os inúmeros desafios colocados para a consolidação da universalização da Educação Infantil para além da obrigatoriedade de matrícula na préescola.

\section{Entre o direito da criança à educação e o dever de ingressar na escola infantil}


A Educação Infantil como direito da criança e dever do estado, previsto na Constituição Federal (1988), completa trinta anos e merece ser comemorado em função dos avanços conquistados, não só em termos de mudança de concepção sobre a função pedagógica, mas na implementação de políticas públicas que orientam a organização do trabalho nas escolas infantis. Como direito público subjetivo e como primeiro direito social do cidadão, a carta constituinte destaca no artigo $6^{\circ}$ que "são direitos sociais a educação, a saúde, a alimentação, o trabalho, a moradia, o lazer, a segurança, a previdência social, a proteção à maternidade e à infância, a assistência aos desamparados, na forma desta Constituição". (BRASIL, 1988)

A carta constituinte destaca no artigo 205 que a educação é um direito de todos e dever do Estado, e será promovida e incentivada com a colaboração da sociedade, além de reiterar, no artigo 206, a “[...] igualdade de condições para o acesso e permanência na escola; a gratuidade do ensino público em estabelecimentos oficiais e a garantia de padrão de qualidade" (BRASIL, 1988).

O Estatuto da Criança e do Adolescente (1990), em consonância com a Constituição, também determina o dever do Estado e da família na preservação dos direitos fundamentais da pessoa humana, por meio do acesso a oportunidades que favoreçam o desenvolvimento físico, mental, moral, espiritual e social, em condições de liberdade e dignidade, tanto da criança, quanto do adolescente (BRASIL, 1990).

A Lei de Diretrizes e Bases da Educação Nacional (1996), ao tratar da composição dos níveis escolares, destaca, no artigo 29, que o objetivo principal da Educação Infantil é “[...] a promoção do desenvolvimento integral da criança nos aspectos físico, afetivo, intelectual, linguístico e social, complementando a ação da família e da comunidade" (BRASIL, 1996). No artigo 30, determina que essa etapa da educação, “[...] será oferecida em creches ou equivalentes, para crianças de até três anos de idade; pré-escolas para crianças de quatro a cinco anos de idade" (BRASIL, 1996). Outro avanço que a lei traz refere-se à avaliação, que não tem a finalidade de promoção ou retenção da criança, pois, no artigo 31, estabelece que “[...] a avaliação far-se-á mediante acompanhamento e registro do seu desenvolvimento, sem o objetivo de promoção, mesmo para o acesso ao ensino fundamental” (BRASIL, 1996).

Desse modo, enquanto a LDB (1996) evidencia a necessidade de se considerar a criança como um todo, para promover seu desenvolvimento integral e sua inserção na esfera pública; a Emenda Constitucional $\mathrm{n}^{\circ}$ 59, aprovada em 2009, ao determinar o ensino obrigatório dos quatro os dezessete anos, a partir de 2016, excluiu a faixa etária de zero a três 
anos de idade Embora seja uma estratégia para assegurar o direito à educação de maneira ampliada para todas as crianças, fragmenta a Educação Infantil, pois, a "[...] obrigatoriedade de frequência das crianças de 4 e 5 anos à escola pode levar à compreensão de que é aí que a educação básica começa, reiterando a antiga cisão entre creches e pré-escolas" (KRAMER; NUNES; CORSINO, 2011, p. 75).

Nessa perspectiva, Cruz (2017, p. 271) ressalta que inserir a criança mais cedo aos conteúdos relacionados à leitura, escrita, números e outros conhecimentos sistematizados, “[...] não torna a criança mais apta para encarar os desafios do ingresso no ensino fundamental; ao contrário, talvez apenas limite suas possibilidades de desenvolvimento e de aprendizagem e produza sentidos de fracasso". Isso porque, no plano pedagógico, a excessiva escolarização da criança, evidenciada pela organização tradicional dos espaços, por atividades e equipamentos pouco adequados à faixa etária, fragmenta a Educação Infantil, que passa a se assemelhar ao ensino fundamental, sobretudo no que tange à organização do tempo, do espaço e da proposta pedagógica.

Vale ressaltar que, anterior a aprovação da EC59/09, a criança que frequentava a préescola ingressou compulsoriamente no primeiro ano, em função da extensão do ensino fundamental de oito para nove anos de duração, o que aconteceu por determinação da Lei $n^{\circ}$. 11.274, de 2006. Essa determinação legal, segundo Cruz (2017, p. 262), “[...] não correspondeu maior integração entre essas duas etapas da educação básica, já que não há nenhum tipo de preparo das crianças da Educação Infantil para o ingresso no ensino fundamental". Do mesmo modo, as escolas de ensino fundamental também não se preocuparam em acolher as crianças de seis anos, “[...] seja em termos de espaço físico, materiais ou currículo, ou ainda em termos de interesse e reconhecimento referentes à vida anterior da criança na pré-escola" (CRUZ, 2017, p. 262).

Flores e Albuquerque (2016, p. 88) argumentam que a imposição legal para a ampliação de vagas na pré-escola, pode "[...] ferir tanto os princípios constitucionais atinentes ao direito à educação básica, quanto a unidade desta primeira etapa educacional garantida na LDB (1996)". Os problemas mais comuns encontrados na realidade das escolas, segundo as autoras, diz respeito ao aumento de turmas em “[...] salas ocupadas sem as devidas adaptações; o travamento na expansão da oferta de vagas para a faixa etária de até três anos, cujo direito se sustenta independente de seu caráter não obrigatório" (FLORES; ALBUQUERQUE, 2016, p. 89). Além disso: 
A intensificação da prática de conveniamento e/ou compra de vagas junto a instituições privadas, muitas destas sem o cumprimento ao conjunto de exigências presentes nas normativas dos respectivos sistemas de ensino; ou, ainda, a redução do atendimento em tempo integral para as turmas de crianças de quatro e cinco anos, cerceando o direito das famílias ao atendimento gratuito em creches e pré-escolas garantido constitucionalmente e ferindo a prioridade da criança no conjunto das políticas sociais (FLORES; ALBUQUERQUE, 2016, p. 89).

Daí a importância no atendimento de critérios de qualidade, segundo Flores e Albuquerque (2016), previstos nos documentos normativos em relação à oferta de vagas, a fim de respeitar os direitos das crianças ao acesso e permanência nas escolas infantis.

Campos (2010, p. 307) reconhece que um dos desafios frente à obrigatoriedade é “[...] garantir que a unidade pedagógica da Educação Infantil seja mantida; isso supõe a adoção de uma efetiva política pública que amplie o acesso e a permanência com qualidade de todas das crianças", não excluindo a creche do processo educacional. Na realidade brasileira, segundo Campos (2010, p. 307), as crianças mais pobres são as que menos têm acesso às creches e pré-escolas, ou seja, “[...] de cada mil crianças entre zero e cinco anos, em média, pertencentes aos $20 \%$ mais pobres da população brasileira, apenas 110 frequentam creche; já nos $20 \%$ mais ricos esse percentual sobe a 350 , ou seja, três vezes mais".

Cruz (2017, p. 270) destaca que a entrada da criança é apenas o primeiro passo na garantia do seu direito à educação. Somado a isso, outras questões, como “[...] recurso financeiro suficiente e processos democráticos de discussão são condições necessárias para que se possa garantir a qualidade da ampliação da obrigatoriedade escolar”.

\footnotetext{
Nessa direção, a escola de Educação Infantil é espaço de ampliação da experiência cultural da criança e de elaboração de conhecimento sobre o vivido, em relações cotidianas ricas e diversificadas; de intenso processo de desenvolvimento da linguagem, da imaginação e de formas culturais de percepção e de memória; de tornar a escrita e a aritmética relevantes à vida; de brincar e se relacionar (CRUZ, 2017, p. 271).
}

A obrigatoriedade do ingresso da criança de quatro anos na pré-escola "[...] por si só não é problema, o problema advém da ausência de políticas públicas para a sua plena efetivação" (TEIXEIRA; ARAÚJO, 2016, p. 112). Caso o poder público cumpra seu papel na implementação de políticas públicas, essa mudança contribuirá especialmente para os filhos dos trabalhadores que têm menos acesso às escolas infantis, segundo Teixeira e Araújo (2006, p. 112). 
Um aspecto que consideramos fundamental é a necessidade de que juntamente com a universalização da pré-escola se universalize ou se fomente a implementação de uma concepção de Educação Infantil que possibilite às crianças a formação de suas máximas qualidades humanas.

No entendimento de Teixeira e Araújo (2006, p. 113), não cabe questionar a pertinência da Emenda Constitucional n ${ }^{\circ} 59$, “[...] mas, formas de como efetivá-la, garantindo que todas as crianças brasileiras na faixa etária de quatro e cinco anos tenham direito a uma Educação Infantil de qualidade referenciada". Além disso, o desafio maior é acolher também as crianças da creche, universalizando, portanto, toda a faixa etária de zero a cinco anos de idade. Assim como Cury (2005, p. 27), acredita-se que “[...] a educação básica deve ser objeto de uma política educacional de igualdade concreta e que faça jus à educação como o primeiro dos direitos sociais", já anunciados na carta constituinte como direito de todos os cidadãos, desde a mais tenra idade.

\section{Cuidar, educar, brincar e incluir: questões para a pré-escola obrigatória}

A finalidade da Educação Infantil, seja na creche ou na pré-escola, envolve quatro processos indissociáveis que se relacionam e se articulam na organização do trabalho pedagógico: cuidados, educação, brincadeiras e inclusão. Isso porque, “[...] os cuidados e educação constituem elos mais que significativos e, portanto, inseparáveis, uma vez que é impossível cuidar de crianças sem educá-las" (PASQUALINI; MARTINS, 2008, p. 78). Na realidade, “[...] o cuidado está presente em alguma medida em todos os níveis de ensino e em toda relação educativa, não constituindo uma dimensão exclusiva ou específica da Educação Infantil”" (PASQUALINI; MARTINS, 2008, p. 79).

Na perspectiva de Pasqualini e Martins (2008), as escolas infantis devem se constituir como espaços educativos, porém, não escolarizantes, assumindo junto às suas finalidades a dimensão do cuidado nas práticas educativas. Essa forma de conceber os espaços coletivos de formação das crianças tem consequências profundas no cotidiano das instituições, pois “[...] acreditamos que é possível pensar nas escolas com as crianças, como lugares nos quais elas sintam vontade de permanecer, lugares acolhedores das suas culturas" (BARBOSA; DELGADO, 2012, p. 10).

Se no decorrer da história a criança foi reconhecida de diferentes maneiras e, por isso, teve diferentes formas de tratamento; na sociedade contemporânea ela tem um lugar 
reconhecido com seus próprios direitos, sobretudo, o direito de vivenciar sua infância por meio de suas diferentes linguagens.

Redin (2012, p. 99) acredita que “[...] falar de linguagens infantis implica falar da linguagem humana, aquela que simboliza, que pode dar sentido e significado ao mundo, mas também aquela que produz o humano". Para essa autora, a comunicação por meio das palavras e as representações simbólicas não são neutras, mas constituídas por construções sociais e culturais. Desse modo:

Falar das linguagens infantis significa, antes de tudo, falar de expressão e também de criação. No início da vida de uma criança, palavras, coisas, pessoas e formas se misturam. A criança vive o mundo plenamente, através de todos os sentidos, experimentando tudo sem a mediação da moral; por isso inventa, faz de conta, ri, repete, em todos os sentidos (REDIN, 2012, p. 100).

A poética infantil, segundo Redin (2012), tem o poder de contagiar os adultos por meio do riso, do choro, da palavra e de tantas outras formas de expressão. Daí a importância de uma escola infantil que promova a ampliação do universo das crianças, pois, nessa nova perspectiva, que busca perceber as capacidades infantis, a criança deixa de ser vista como um ser passivo e passa a ser considerada como um ser ativo, capaz de aprender desde muito pequena. Essa capacidade de aprendizagem acontece, pois, o perfil da criança da pré-escola se caracteriza pela imaginação, pela curiosidade, pelo movimento e pelo desejo de aprender, aliados à sua forma privilegiada de conhecer o mundo, sobretudo por meio das brincadeiras.

Para Vygotsky (2008), a brincadeira tem um papel importante no desenvolvimento da criança, pois o domínio da realidade se torna mais compreensível e favorece sua inserção social. Isso porque a brincadeira é considerada atividade principal na infância, visto que ocorrem as mais importantes mudanças no desenvolvimento, “[...] dentro da qual se desenvolvem processos psíquicos que preparam o caminho da transição da criança para um novo e mais elevado nível de desenvolvimento" (LEONTIEV, 2001, p. 122). São por meio dessas atividades que ela aprende e se desenvolve na apropriação do uso de objetos, na interação com outras pessoas, na internalização de normas de convívio e nas relações sociais (LEONTIEV, 2001).

A fim de garantir que as brincadeiras se façam presentes nas instituições, as Diretrizes Curriculares Nacionais para a Educação Infantil (2009) determinam que a proposta pedagógica deve ter como objetivo “[...] garantir à criança acesso a processos de apropriação, 
renovação e articulação de conhecimentos e aprendizagens de diferentes linguagens, dentre elas, o direito à brincadeira" (BRASIL, 2009, p. 18).

Daí a importância da proposta pedagógica preservar a característica etária e a integração entre educação, cuidado e brincadeiras, favorecendo o desenvolvimento pleno das crianças nos aspectos físico, psicológico, cognitivo, emocional, estético e social, buscando a integração com a família e a comunidade (PASCHOAL; MORENO, 2009). Isso significa prever diversos tipos de atividades, brincadeiras e situações pedagógicas orientadas que envolverão a jornada diária das crianças e dos adultos, sobretudo nos momentos que envolvem a rotina da instituição.

Para Dahlberg; Moss e Pence (2004), a escola deve dar oportunidade para as crianças trabalharem juntas na exploração e na interpretação do mundo que as cerca, pois será dessa maneira que elas assumirão a responsabilidade da própria aprendizagem. Criar condições para um ambiente rico em oportunidades de desenvolvimento da criança e de seus profissionais é condição necessária para uma educação emancipatória na pré-escola.

O que se propõe, segundo Dahlberg, Moss e Pence (2004), é que as escolas busquem aproximar cultura, linguagem, cognição e afetividade como elementos constituintes do desenvolvimento humano e voltados para a construção da imaginação, da fantasia, da criatividade e das brincadeiras. Dessa forma, as escolas infantis têm como objetivo principal mediar o processo de construção de conhecimentos e habilidades das crianças com necessidades educacionais especiais ou não, já que todas têm nessas instituições a possibilidade de viver novas situações de aprendizagens; trocando experiências e construindo suas identidades.

Do ponto de vista da atuação docente, é necessário "[...] o reconhecimento das especificidades etárias, das singularidades individuais e coletivas das crianças, promovendo interações entre crianças de mesma idade e crianças de diferentes idades" (BRASIL, 2009, p. 19). Nas palavras de Oliveira (2002, p. 249), as crianças com "[...] necessidades educativas especiais são crianças iguais às outras, apesar das diferenças, e devem, isto sim, ser trazidas para enriquecer os processos de aprendizagem". Para essa autora é importante lembrar que "todas as crianças sem exceção, têm eficiências e deficiências em suas formas de se relacionar com o mundo e a de que devemos trabalhar para a ampliação de suas eficiências" (OLIVEIRA, 2002, p. 250).

Mantoan (2003), assim como Oliveira (2002), argumenta que se a inclusão é produto de uma educação plural, democrática e transgressora, também a criança da "[...] escola 
inclusiva é outro sujeito, que não tem uma identidade fixada em modelos ideais, permanentes, essenciais” (MANTOAN, 2003, p. 20). Na realidade, pode-se afirmar que:

A inclusão também se legitima, porque a escola, para muitos alunos, é o único espaço de acesso aos conhecimentos. É o lugar que vai proporcionar lhes condições de se desenvolverem e de se tornarem cidadãos, alguém com uma identidade sociocultural que lhes conferirá oportunidades de ser e de viver dignamente (MANTOAN, 2003, p. 30).

Além disso, tanto a creche quanto a pré-escola devem se constituir em espaços acolhedores, educativos, inclusivos, visto que são nesses espaços que se "[...] pode intencionalmente organizar as condições adequadas de vida e educação para garantir a máxima apropriação das qualidades humanas" (MELLO, 2007, p. 85).

O trabalho coletivo é primordial, pois a consolidação de um ambiente inclusivo só é possível no reconhecimento das necessidades de cada um e, ao mesmo tempo "[...] da construção de um projeto pedagógico que parta do respeito aos potenciais disponíveis e da articulação das relações na produção de um coletivo no qual todos se reconheçam como participantes" (SEKKEL; ZANELATTO; BRANDÃO, 2010, p. 125). Por isso, defende-se uma educação que tenha como objetivo principal mediar o processo de construção de conhecimentos e habilidades por parte de todas as crianças; uma educação solidária, com práticas coletivas de trocas de experiências e apropriação verdadeira da cidadania (KRAMER, 2003).

Sobre essa questão, Cury (2005, p. 28) explica, que sendo a educação básica um direito do cidadão e dever do Estado, as pessoas com necessidades educacionais especiais e “[...] os grupos sociais como o dos afro-descendentes, devem ser sujeitos de um atendimento que leve à desconstrução de estereótipos, preconceitos e discriminações", sobretudo no contexto escolar. Para Cury (2005, p. 29):

É certo que as dificuldades para a realização de um ideal igualitário e universalista, propugnado pelo Estado de bem-estar social, ensejou o surgimento efetivo de lacunas, dando margem à separação da defesa do direito à diferença de sua base fundante no direito à igualdade. Sem esse último, o direito à diferença corre o risco de políticas erráticas e flutuantes ao sabor de cada diferença.

Apesar da unanimidade entre poder público, sociedade civil e pesquisadores da infância acerca do direito da criança à educação desde o nascimento, o desafio é consolidar, efetivamente, não só os direitos no âmbito educativo, mas garantir todos os outros previstos 
nas leis para todas as crianças brasileiras. Repensar o atendimento oferecido às populações infantis, em espaços coletivos, requer um compromisso permanente das diferentes instâncias, no sentido de oferecer políticas públicas que garantam, na prática, a efetivação do direito à vida, à moradia, à educação de qualidade, e, sobretudo no direito à inclusão social e educacional.

\section{Considerações finais}

As últimas décadas avançaram em termos de legislação e políticas públicas para a Educação Infantil no Brasil, pois além do reconhecimento da criança como sujeito de direitos na sociedade, o poder público resguardou o seu direito à educação desde o nascimento. Assim, constata-se que a função principal dessas instituições é a promoção do desenvolvimento pleno da criança, por meio do trabalho pedagógico que integra os cuidados, a educação, as brincadeiras e a inclusão das crianças com necessidades educacionais especiais.

Por outro lado, a implementação da obrigatoriedade da pré-escola “[...] exigirá, dos gestores públicos, forte empenho e responsabilidade, evitando-se que a expansão da oferta educativa em pré-escolas penalize o acesso das crianças de zero-três anos à educação, conforme é seu direito também" (CAMPOS, 2010, p. 304). O desafio a partir dessa nova configuração é a concretização efetiva de uma educação de qualidade, que promova a ampliação dos saberes das crianças de zero a cinco anos de idade e o enriquecimento das suas diferentes linguagens.

Isso porque, as contradições entre o que é determinado pelas leis e o que é, realmente, efetivado no contexto da Educação Infantil, ainda é realidade no país. As reformas educacionais implementadas após a década de noventa, apesar de pretenderem "[...] modernizar os sistemas educacionais, não extinguiram estruturas que mantêm a educação ainda como um privilégio de poucos. Isto decorre da conservação de mecanismos excludentes, no interior dos sistemas educativos". (CAMPOS, 2010, p. 300)

Por esse motivo, com a obrigatoriedade do ingresso da criança na escola infantil aos quatro anos de idade, “[...] corre-se o risco de desvincular a Educação Infantil dos princípios formulados para a creche e a pré-escola e não se enfrentar a verticalidade do processo escolar" (KRAMER; NUNES; CORSINO, 2011, p. 76), se distanciando das normativas legais e das propostas curriculares para essa etapa da educação. 
Outro grande desafio é a superação de práticas escolarizantes de alfabetização em favor de uma educação que acolhe, que humaniza e que reconheça a inclusão como direito da criança. Daí a importância da formação inicial e continuada dos professores e a valorização profissional, em termos de carreira e salários, como condição primordial para a consolidação dessa etapa da Educação Básica.

\section{REFERÊNCIAS}

BARBOSA, M. C. S.; DELGADO, A. C. C. (Orgs). A Infância no ensino fundamental de nove anos. Porto Alegre: Penso, 2012.

BRASIL. Constituição da República Federativa do Brasil. Brasília, DF: Senado Federal, 1988.

BRASIL. Estatuto da Criança e do Adolescente. Lei nº 8.069, de 13 de junho de 1990.

BRASIL. Lei de Diretrizes e Bases da Educação Nacional. Lei n ${ }^{\circ}$ 9394, de 20 de dezembro de 1996. Dispõe sobre as Diretrizes e Bases da Educação Nacional. Brasília, DF: MEC, 1996.

BRASIL. Ministério da Educação. Secretaria de Educação Especial. Diretrizes Nacionais para a Educação Especial na Educação Básica. Brasília: MEC/SEESP, 2001

BRASIL. Ministério da Educação e do Desporto. Secretaria de Educação Básica. Política nacional de educação infantil. Brasília, DF: MEC/SEB, 2006.

BRASIL. Emenda Constitucional n ${ }^{\circ}$ 59, de 11 de novembro de 2009. Acrescenta § 3o ao artigo 76 do ato das disposições constitucionais transitórias. Diário Oficial da União, 12 nov. 2009. Seção 1, p.8.

BRASIL. Lei $\mathbf{n}^{\mathbf{0} 12.796}$ de 04 de abril de 2013. Altera a Lei ${ }^{\circ} 9.394$ de 20 de dezembro de 1996-LDB. Brasília: 2013.

CAMPOS, R. F. Democratização da educação infantil: As concepções e políticas em debate. Revista Retratos da Escola, Brasília, v. 4, n. 7, p. 299-311, jul./dez., 2010.

CURY, C. R. J. Políticas inclusivas e compensatórias na educação básica. Cadernos de Pesquisa, v. 35, n. 124, p. 11-32, jan./abr., 2005.

CRUZ, M. N. da. Educação infantil e ampliação da obrigatoriedade escolar: implicações para o desenvolvimento cultural da criança. Cad. Cedes, Campinas, v. 37, n. 102, p. 259-276, maio/ago., 2017.

DAHLBERG, G.; MOSS, P.; PENCE, A. Qualidade na educação da primeira infância: perspectivas pós-modernas. trad. Magda França Lopes. Porto Alegre: Artmed, 2004. 
FARENZENA, N. A Emenda da obrigatoriedade: mudanças e permanências. Revista Retratos da Escola. Brasília, v. 4, n. 7, p. 197-209, jul./dez., 2010.

FLORES, M. L. R.; ALBUQUERQUE, S. dos S. Direito à educação no contexto da obrigatoriedade de matrícula escolar na pré-escola. Revista Textura Canoas, v. 18, n. 36, p. 87-110, jan./abr., 2018.

KRAMER, S. Infância, cultura contemporânea e educação contra a barbárie. In: BAZÍLIO, L. C.; KRAMER, S. Infância, educação e direitos humanos. São Paulo: Cortez, 2003. p. 83106.

KRAMER, S.; NUNES, M. F. R.; CORSINO, P. Infância e crianças de 6 anos: desafios das transições na educação infantil e no ensino fundamental. Revista Educação e Pesquisa, São Paulo, v. 37, n. 1, p. 69-85, jan./abr., 2011.

LEONTIEV, A. Os princípios psicológicos da brincadeira escolar. In: VYGOTSKY, L. et al. Linguagem, desenvolvimento e aprendizagem. 7. ed. São Paulo: EPU, 2001.

MANTOAN, M. T. E. Inclusão escolar: O que é? Por quê? Como fazer? São Paulo: Moderna, 2003. (Coleção cotidiano escolar)

MELLO, S. A. Infância e humanização: algumas considerações na perspectiva históricocultural. Revista Perspectiva, Florianópolis, v. 25, n. 1, p. 83-104, jan./jun., 2007.

MORENO, G. L.; PASCHOAL, J. D. A criança de seis anos no ensino fundamental: considerações iniciais. IN: BRANDÃO, C. da F.; PASCHOAL, J. D. (orgs). Ensino Fundamental e nove anos: teoria e prática na sala de aula. Ed. Avercamp, 2009. p. 37-50.

NASCIMENTO, M. L. Algumas considerações sobre a infância e as políticas de educação infantil. Revista Educação \& Linguagem, v. 14, n. 23, p. 146-159, 2011.

OLIVEIRA, Z. M. R. de. Educação Infantil: fundamentos e métodos. São Paulo: Cortez, 2002.

PASQUALINI, J. C.; MARTINS, L. M. A Educação Infantil em busca de identidade: análise crítica do binômio "cuidar-educar" e da perspectiva anti-escolar em Educação Infantil.

Revista Psicologia da Educação, São Paulo, n. 27, p. 71-100, 2008.

PINAZZA, M. A.; SANTOS, M. W. A (pré)-escola na lógica da obrigatoriedade: um desconcertante 'dejà vu'?. Revista Textura Canoas, v. 18, n. 36, p. 22-43, 2016.

REDIN, M. M. Múltiplas linguagens na infância: um mundo cheio de girabelhinhas. In: BARBOSA, M. C. S.; DELGADO, A. C. C. (Orgs). A Infância no ensino fundamental de nove anos. Porto Alegre: Penso, 2012. p. 99-106.

SEKKEL, M. C.; ZANELATTO, R.; BRANDÃO, Suely de Barros. Ambientes inclusivos na educação infantil: possibilidades e impedimentos. Revista Psicologia em Estudo. Maringá, v. 15, n. 1, p. 117-126, jan./mar., 2010. 
TEIXEIRA, S. R. dos S.; ARAÚJO, A. P. M. de. Contribuições da teoria histórico cultural para a universalização da pré-escola no Brasil. Revista Textura Canoas, v. 18, n. 36 p. 111132, jan./abr., 2016.

VYGOTSKY, L. S. A formação social da mente: o desenvolvimento dos processos psicológicos superiores. 7. ed. São Paulo: Martins Fontes, 2008.

\section{Como referenciar este artigo}

PASCHOAL, Jaqueline Delgado. A inclusão na pré-escola obrigatória: uma análise da legislação. Revista Ibero-Americana de Estudos em Educação, Araraquara, v. 14, n. esp. 1, p. 656-670, abr., 2019. E-ISSN: 1982-5587. DOI: 10.21723/riaee.v14iesp.1.12197

Submetido em: 06/08/2018

Aprovado em: 21/09/2018 